\title{
Retinal ganglion cell-conditioned medium and surrounding pressure alters gene expression and differentiation of rat retinal progenitor cells
}

\author{
MIN DAI ${ }^{1-5}$, QING ZHANG ${ }^{1-5}$, ZHIKUN ZHENG $^{1-5}$ and JIANZHOU WANG ${ }^{6}$ \\ ${ }^{1}$ Department of Ophthalmology; ${ }^{2}$ Key Laboratory of Yunnan Province for The Prevention and Treatment of Ophthalmology; \\ ${ }^{3}$ Provincial Innovation Team for Cataract and Ocular Fundus Disease; ${ }^{4}$ Yunnan Eye Institute; \\ ${ }^{5}$ Expert Workstation of Yao Ke, Second People's Hospital of Yunnan Province, Kunming, Yunan 650021; \\ ${ }^{6}$ Department of Ophthalmology, Yan'an Hospital, Kunming, Yunan 650051, P.R. China
}

Received March 13, 2017; Accepted December 4, 2017

DOI: $10.3892 / \mathrm{mmr} .2018 .8738$

\begin{abstract}
Loss of retinal ganglion cells is implicated in glaucoma and high intraocular pressure. Factors that affect the differentiation of retinal progenitor cells into retinal ganglion cells remain unclear. The present study aimed to investigate the effects of retinal ganglion cell-conditioned medium on gene expression and differentiation in retinal progenitor cells, and the effects of surrounding pressure on the survival and differentiation of retinal progenitor cells. Retinal progenitor cells and retinal ganglion cells were isolated from rats. Immunofluorescence staining of Nestin and Thyl was performed to identify rat retinal progenitor cells and retinal ganglion cells, respectively. Retinal progenitor cells and ganglion cells were cultured for $48 \mathrm{~h}$ under surrounding pressure of $0,20,40,60$ and $80 \mathrm{mmHg}$. Cellular apoptosis was detected using a caspase- 3 assay kit. In addition, the culture supernatant of rat retinal ganglion cells was collected. Retinal progenitor cells were cultured in the presence or absence of retinal ganglion-conditioned medium for $72 \mathrm{~h}$ under normal pressure. Gene expression of Nestin, paired box protein 6 (PAX6), Thyl and brain-specific homeobox/POU domain protein 3 (Brn-3) in retinal progenitor cells was detected by reverse transcription-quantitative polymerase chain reaction. Retinal progenitor cells were cultured in retinal ganglion-conditioned medium for $72 \mathrm{~h}$ under surrounding pressure of 0 and $40 \mathrm{mmHg}$, respectively, and flow cytometry was utilized to evaluate the effects of pressure on the differentiation of retinal progenitor cells into retinal ganglion cells. The results demonstrated that isolated retinal progenitor
\end{abstract}

Correspondence to: Dr Jianzhou Wang, Department of Ophthalmology, Yan'an Hospital, 245 Renmin East Road, Panlong, Kunming, Yunan 650051, P.R. China

E-mail: yayywjz@163.com

Key words: retinal progenitor cells, retinal ganglion cells, pressure, Nestin, Thyl cell surface antigen cells were Nestin-positive and retinal ganglion cells were Thyl-positive, suggesting successful isolation. The activity of caspase-3 increased in retinal progenitor cells and retinal ganglion cells in a pressure-dependent manner. When the surrounding pressure reached 40,60 and $80 \mathrm{mmHg}$, the activity of caspase-3 in retinal progenitor cells and ganglion cells increased significantly compared with cells that were not under pressure. Compared with retinal progenitor cells cultured without ganglion-conditioned medium, those cultured with ganglion-conditioned medium had significantly decreased expression levels of Nestin and PAX6, and increased expression levels of Thy1 and Brn3. Compared with $0 \mathrm{mmHg}$ pressure, retinal progenitor cells cultured in ganglion-conditioned medium under $40 \mathrm{mmHg}$ pressure had increased percentages of Thy1-positive cells. In conclusion, the apoptosis of rat retinal progenitor cells and retinal ganglion cells was pressure-dependent. Retinal ganglion cell-conditioned medium increased the differentiation of retinal progenitor cells into retinal ganglion-like cells, and the differentiation increased as surrounding pressure increased. Current study provides insights that may contribute to the efforts of developing a treatment for glaucoma.

\section{Introduction}

Glaucoma is the second-leading cause of blindness globally, following cataracts. There were 44.7 million people in the world with open angle glaucoma as of 2010 (1). Glaucoma is a group of eye diseases that result in damage to the optic nerve and vision loss. Increased intraocular pressure is the most important risk factor in the majority of glaucoma cases (2).

Retinal ganglion cells transmit visual information from the retina in the form of action potentials to the thalamus, hypothalamus and midbrain. They have a long axon that extends into the brain, forming the optic nerve, optic chiasm and optic tract. Loss of retinal ganglion cells has been implicated in a wide range of glaucoma stages, from preperimetric to advanced (3). An observational cohort study that examined 116 eyes of 62 glaucoma patients revealed that the rate of retinal ganglion cell loss resulted in improved detection of glaucoma progression, 
compared with either optical coherence tomography or standard automated perimetry (4). In addition, transplanted stem cells were reported to migrate into and integrate in different layers of the retina (5). Therefore, in order to pave the foundation for retinal ganglion cell therapy for glaucoma, it is of importance to investigate the factors that may affect differentiation of retinal progenitor cells into retinal ganglion cells.

Fibroblast growth factor 2 was revealed to induce embryonic stem cell-derived neural progenitors to generate retinal ganglion cell-like cells in vitro (6). The combination of retinal pigment epithelial cell-conditioned medium and photoreceptor outer segments stimulated mesenchymal stem cell differentiation toward retinal pigment epithelial cell phenotype (7). However, the effects of retinal ganglion cell-conditioned medium on the gene expression and differentiation of retinal progenitor cells and the effects of surrounding pressure on the survival and differentiation of retinal progenitor cells remain unclear.

Nestin is a neuroectodermal stem cell marker, and is expressed in retinal progenitor cells (8). Upon differentiation, Nestin becomes down-regulated. Paired box protein (PAX)6 is a key regulatory gene of eye development (9). Retinal progenitor cell clones were established by transfection of the paired box protein 6 (PAX6) gene into mouse induced pluripotent stem cells (10). Thyl is a surface glycoprotein uniquely expressed in retinal ganglion cells in the retina (11). Brain-specific homeobox/POU domain protein 3 (Brn3) is involved in the regulation of differentiation, dendritic stratification and axonal projection of retinal ganglion cells during development (12). Therefore, Nestin and PAX6 were utilized to identify retinal progenitor cells, and Thyl and Brn3 were used to identify retinal ganglion cells. The retinal ganglia are a type of neuron near the inner surface of the retina. They transmit image-forming and non-image forming visual information from the retina to the thalamus, hypothalamus, mesencephalon and midbrain in the form of action potentials. Examining the differentiation of retinal progenitor cells into retinal ganglion cells may provide insights into vision restoration following injury in glaucoma. Therefore, the present study aimed to investigate the effects of retinal ganglion cell-conditioned medium on gene expression and differentiation in retinal progenitor cells, and the effects of surrounding pressure on the survival and differentiation of retinal progenitor cells.

\section{Materials and methods}

Reagents and equipment. Dulbecco's modified Eagle's medium (DMEM)/F12, B27, N2, heparin and glutamine were purchased from Thermo Fisher Scientific, Inc. (Waltham, MA, USA). Epithelial growth factor (EGF) and basic fibroblast growth factor (bFGF) were purchased from Sigma-Aldrich; Merck KGaA (Darmstadt, Germany). Trypsin (Invitrogen; Thermo Fisher Scientific, Inc.), bicinchoninic acid assay kit, caspase-3 assay kit (Sigma-Aldrich; Merck KGaA), PBS (Sigma-Aldrich; Merck KGaA), were used in the present study. Anti-Nestin antibody, anti-Thy1 antibody and secondary antibody were purchased from Abcam (Cambridge, UK). Secondary antibodies included goat anti-rabbit immunoglobulin (Ig)G H\&L (Alexa Fluor ${ }^{\circledR}$ 488; cat. no. ab150077; Abcam, Cambridge, UK), and donkey anti-rabbit IgG H\&L (Alexa Fluor ${ }^{\circledR}$ 555; cat. no. ab150074; Abcam). Primers and probes, TRIzol reagent,
SuperScript III Reverse Transcriptase, SYBR-Green I and DEPC $\mathrm{H}_{2} \mathrm{O}$ were purchased from Invitrogen (Thermo Fisher Scientific, Inc.). RNase inhibitor was purchased from Fermentas (Thermo Fisher Scientific, Inc.). Platinum Taq DNA polymerase, oligo dT/primer and $100 \mathrm{mM}$ dNTPs were purchased from Invitrogen (Thermo Fisher Scientific, Inc.).

The following equipment was used: Cell incubator (Thermo Fisher Scientific, Inc.), light microscope (Olympus Corporation, Tokyo, Japan), CFX96 Touch $^{\mathrm{TM}}$ Real-Time polymerase chain reaction (PCR) Detection system (Bio-Rad Laboratories, Inc., Hercules, CA, USA), table-type refrigerated centrifuge, plate reader (Zhengzhou Nanbei Instrument Equipment, Inc., Hefei, China), LSRII flow cytometer (BD Biosciences, Franklin Lakes, NJ, USA) and FlowJo software 7.6.2 (FlowJo LLC, Ashland, OR, USA).

Isolation and culture of rat retinal progenitor cells. A total of 20 Sprague Dawley ${ }^{\circledR}$ (SD) rats (male; 17 days old; 35-55 g; Shanghai SLAC Laboratory Animal, Inc., Shanghai, China) were sacrificed. Animals were raised at $25^{\circ} \mathrm{C}$ with $65 \%$ humidity in normal atmosphere. Animals had free access to food and water and were housed under $12 \mathrm{~h}$ light/dark cycle.

Retinal pigment tissue at the ciliary margin zone of embryos was isolated under a microscope, and placed into cold PBS. The tissue was cut into small sections, and digested with $0.1 \%$ trypsin at $37^{\circ} \mathrm{C}$ for $10 \mathrm{~min}$. DMEM/F12 supplemented with $20 \%$ fetal bovine serum (FBS, Gibco; Thermo Fisher Scientific, Inc.) was added to stop digestion by trypsin. Trypsin (0.01\%; Gibco; Thermo Fisher Scientific, Inc.) was added at room temperature for $20 \mathrm{~min}$, and a single cell suspension was prepared by pipetting gently. The cell suspension was centrifuged at $500 \mathrm{x}$ g for $5 \mathrm{~min}$ at room temperature, and cell pellet was resuspended in DMEM/F12 supplemented with $2 \% \mathrm{~B} 27,1 \% \mathrm{~N} 2$, heparin $(90 \mu \mathrm{g} / \mathrm{ml})$, glutamine $(2 \mathrm{mmol} / \mathrm{l})$, EGF $(20 \mathrm{ng} / \mathrm{ml})$ and basic fibroblast growth factor (bFGF; $10 \mathrm{ng} / \mathrm{ml})$. The cell suspension was filtered $(0.22 \mu \mathrm{m}$ pores $)$ and cultured in plates $\left(25 \mathrm{~cm}^{2}\right)$ at $37^{\circ} \mathrm{C}$ in $5 \% \mathrm{CO}_{2}$ and $95 \%$ air. Cell culture medium was replaced every 3 days. The current study was approved by the Animal Research Board of Second People's Hospital and Yan'an Hospital (Kunming, China). All efforts were made to reduce animal suffering.

Isolation and culture of rat retinal ganglion cells. A total of 20 SD rats (7 days old; male; 15-20 g; Shanghai SLAC Laboratory Animal, Inc.) were sacrificed. Animals were raised at $25^{\circ} \mathrm{C}$ with $65 \%$ humidity in normal atmosphere. Animals had free access to food and water and were housed under $12 \mathrm{~h}$ light/dark cycle. Eyeballs were removed using aseptic technique, and washed with PBS three times. The cornea was removed followed by the limbus corneae, lens and vitreous body. The neuronal layer of the retinal tissue was isolated, washed with PBS supplemented with $1 \%$ penicillin-streptomycin three times and digested with $0.05 \%$ trypsin at $37^{\circ} \mathrm{C}$ for $30 \mathrm{~min}$. The digestion was terminated by adding DMEM containing $10 \% \mathrm{FBS}$. The cell suspension was filtered with a $40 \mu \mathrm{m}$ filter, and centrifuged at $500 \mathrm{x}$ g at room temperature for $5 \mathrm{~min}$. The cell pellet was resuspended with DMEM and cultured in plates at $37^{\circ} \mathrm{C}$ in $5 \% \mathrm{CO}_{2}$ and $95 \%$ air.

Pressure treatment. Cells $\left(1 \times 10^{5}\right)$ were plated in a $3.5 \mathrm{~cm}$ culture dish 1 day prior to the experiments. The bottom of a bag 
containing normal saline (Fig. 1A) was cut open with scissors, and the normal saline was poured out. The culture dish was placed into the empty bag, and the bottom was sealed using a plastic envelope machine. Sphygmomanometer (Jiangsu Yuyue Medical Equipment \& Supply Co., Inc., Nanjing, China; Fig. 1B) was utilized to pump air into the bag, and the pressure was measured using the instrument. Cells in the different experimental groups were treated with various pressures at room temperature for $48 \mathrm{~h}$ using this method.

Immunofluorescence. Rat retinal progenitor cells and ganglion cells were isolated, and cultured in 24-well plates with cover slips ( $3 \times 10^{4}$ cells $/ \mathrm{cm}^{2} ; 50 \%$ confluence). Cells adhered to cover slips were then fixed in $4 \%$ paraformaldehyde at room temperature for $10 \mathrm{~min}$, and blocked with $2 \%$ bovine serum albumin (Sigma-Aldrich; Merck KGaA) for $30 \mathrm{~min}$ at room temperature. Rat retinal progenitor cells were incubated with a primary antibody against Nestin (1:500; cat. no. ab92391), and retinal ganglion cells were incubated with a primary antibody against Thy1 (1:500; cat. no. ab133350) at $4^{\circ} \mathrm{C}$ overnight. Following overnight incubation, cover slips were washed with PBS, and incubated in the dark with fluorescein isothiocyanate-conjugated goat anti-rabbit secondary antibody $(1: 1,000)$ at room temperature for $1 \mathrm{~h}$. Cover slips were washed with PBS and stained with DAPI at room temperature for $5 \mathrm{~min}$. Slides were prepared using an anti-quenching mounting medium. Slides were observed using a fluorescence microscope (magnification, x100).

Apoptosis assay. Retinal progenitor cells and ganglion cells were cultured for $48 \mathrm{~h}$ under surrounding pressures of $0,20,40,60$ and $80 \mathrm{mmHg}$, respectively. Cell apoptosis was detected using a caspase-3 assay kit (BioVision,Inc., Milpitas, CA,USA) according to the manufacturer's protocol. Proteins from retinal stem cells and ganglion cells were extracted using cell lysis buffer from the caspase-3 assay kit, and the protein concentration was measured using a bicinchoninic acid assay kit. Acetyl-Asp-Glu-Val-Asp p-nitroanilide (Ac-DEVD-pNA; included in the caspase-3 assay kit), the substrate that is hydrolyzed by caspase-3, was mixed with cell proteins at $37^{\circ} \mathrm{C}$ for $2 \mathrm{~h}$, and the optical density values were measured at an absorbance of $405 \mathrm{~nm}$ using a plate reader. Experiments were repeated three times.

Induction of retinal progenitor cell differentiation by retinal ganglion cell-conditioned medium. Rat retinal ganglion cells were cultured to $80 \%$ confluence, and the cell culture medium was replaced with DMEM/F12 medium without serum. Retinal ganglion cells were cultured for a further $24 \mathrm{~h}$, and the culture supernatant was collected. Retinal progenitor cells were cultured in retinal ganglion cell-conditioned medium for $72 \mathrm{~h}$ under normal pressure, or under $40 \mathrm{mmHg}$ pressure. Retinal progenitor cells that were cultured without retinal ganglion cell-conditioned medium served as control (no treatment). Retinal progenitor cells were collected. Gene expression levels of Nestin, PAX6, Thy1 and Brn-3 were detected by reverse transcription-quantitative PCR (RT-qPCR), and flow cytometry was utilized to evaluate the effects of pressure on the differentiation of retinal progenitor cells into retinal ganglion cells.

$R T-q P C R$. Following induction by retinal ganglion cell-conditioned medium, retinal progenitor cells under normal pressure
A

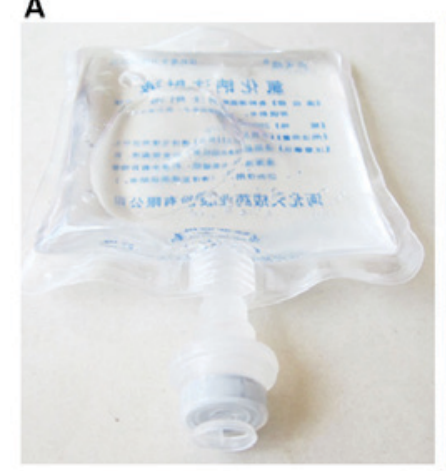

B

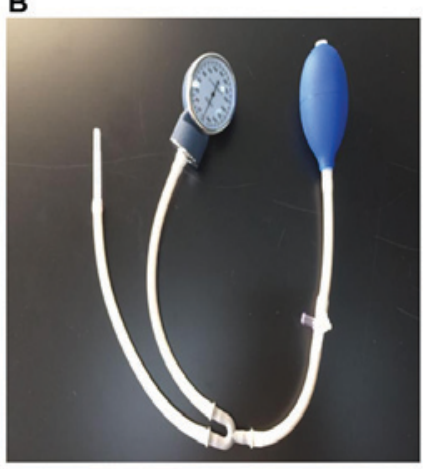

Figure 1. Pressure treatment of cells. (A) A normal saline bag was used to contain the culture dish. (B) Sphygmomanometer. Cells $\left(1 \times 10^{5}\right)$ were plated in a $3.5 \mathrm{~cm}$ culture dish 1 day prior to experiments. The bottom of a bag containing normal saline was cut open with scissors and the contents was poured out. The culture dish was placed into the empty bag, and the bottom was sealed with a plastic-envelope machine. A pressure instrument was utilized to pump air into the bag, and the pressure was measured using the instrument. Cells in the different experimental groups were treated with various pressures using this method.

were collected. Total RNA was extracted using TRIzol reagent, following the manufacturer's protocol. A universal cDNA synthesis kit (Invitrogen; Thermo Fisher Scientific, Inc.) was utilized for reverse transcription. Each reaction contained $0.5 \mu 1$ random primers $(0.2 \mu \mathrm{g} / \mu \mathrm{l})$ and $1 \mu \mathrm{l}$ SuperScript III reverse transcriptase $(200 \mathrm{U} / \mu \mathrm{l})$. The specific primer for Nestin was forward, CTGGAAGGTGGGCAGCAACT and reverse, TCT CAAGGGTATTAGGCAAGGG; the primer for PAX6 was forward, CTGGAGTGTCAGTTCCCGTC and reverse, ATA CCGTGCCTTCTGTACGC; the primer for Thyl was forward, CAAAACGCGGGGAGAAATGG and reverse, CTGGTG TTCCATCGGGTCTC; and the primer for Brn-3 was forward, TTTCCCCCTTTGTTCCGCTT and reverse, GCCTAATGA CGCCTAGCCAA. PCR was performed by utilizing a SYBR qPCR mix kit (Invitrogen; Thermo Fisher Scientific, Inc.). PCR conditions were as follows: Predenaturation at $95^{\circ} \mathrm{C}$ for $2 \mathrm{~min}$, 40 cycles of denaturation at $95^{\circ} \mathrm{C}$ for $10 \mathrm{sec}$ and annealing and polymerization at $60^{\circ} \mathrm{C}$ for $30 \mathrm{sec}$ and $70^{\circ} \mathrm{C}$ for $45 \mathrm{sec}$. PCR was performed using a CFX96 Touch $^{\text {TM }}$ Real-Time PCR Detection system (Bio-Rad Laboratories, Inc.). Gene expression was determined and normalized to $\beta$-actin. The following rat $\beta$-actin primers were used: Forward, 5'AGGGAAATCGTG CGTGAC3' and reverse, 5'CGCTCATTGCCGATAGTG3'. The $2^{-\Delta \Delta C q}$ method was utilized to measure PCR results (13).

Flow cytometry. Following induction with retinal ganglion cell-conditioned medium, retinal progenitor cells were cultured under surrounding pressure of 0 and $40 \mathrm{mmHg}(50 \%$ confluence) at $37^{\circ} \mathrm{C}$ for $48 \mathrm{~h}$. Cells were washed with PBS twice, and incubated with trypsin at $37^{\circ} \mathrm{C}$ for $1 \mathrm{~min}$. Following digestion, the cell suspension was centrifuged at $400 \mathrm{x} g$ at room temperature for $5 \mathrm{~min}$. The cell pellet was resuspended with PBS and the centrifugation and resuspension steps were repeated a further two times. Cells were fixed in $4 \%$ paraformaldehyde at room temperature for $10 \mathrm{~min}$, and blocked with $2 \%$ bovine serum albumin (Sigma-Aldrich; Merck KGaA) for $30 \mathrm{~min}$ at room temperature. Anti-Thy1 antibody $(10 \mu \mathrm{l} ; 1: 200)$ was added to $100 \mu \mathrm{l}$ cell suspension, and incubated at $4^{\circ} \mathrm{C}$ for 


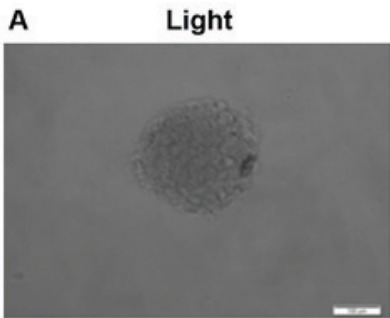

B

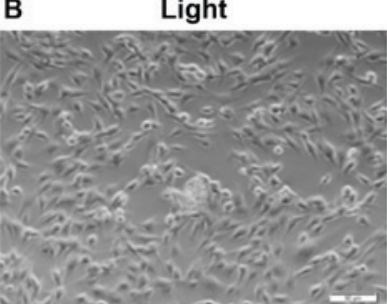

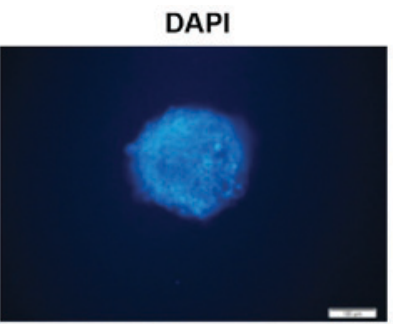

DAPI

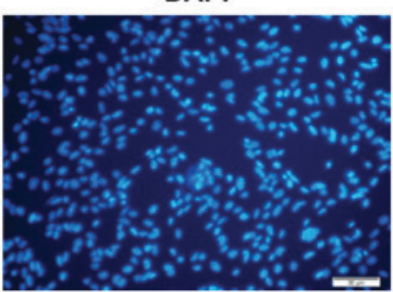

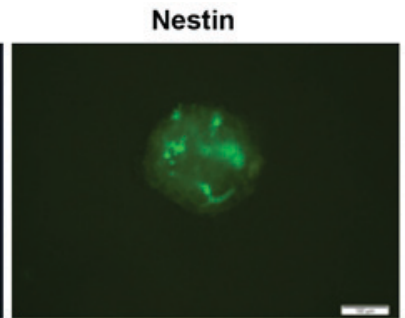

Thy1

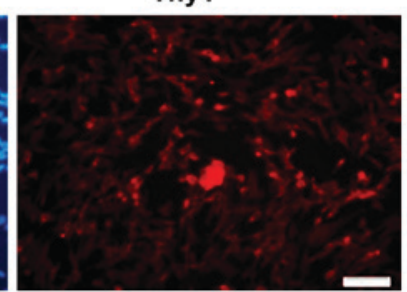

Figure 2. Identification of rat retinal progenitor cells and retinal ganglion cells. (A) Retinal progenitor cells and (B) retinal ganglion cells. Retinal progenitor cells and retinal ganglion cells were isolated from rats. Immunofluorescence was utilized to identify these cells. Rat retinal progenitor cells were stained with a primary antibody against Nestin, and retinal ganglion cells were stained with a primary antibody against Thyl. Isolated retinal progenitor cells were Nestin-positive (green), and retinal ganglion cells were Thyl-positive (red), which suggested a successful isolation. The cell nucleus was stained with DAPI (blue). Cell images captured under a light microscope are depicted in the leftmost panels. Scale bar, $100 \mu \mathrm{m}$.

$30 \mathrm{~min}$. Cells were centrifuged at $400 \mathrm{x} \mathrm{g}$ at room temperature for 5 min, and resuspended with PBS three times. Secondary green fluorescent protein-labeled goat anti-rabbit IgG $\mathrm{H} \& \mathrm{~L}$ antibody (Alexa Fluor ${ }^{\circledR}$ 488; cat. no. ab150077; 1:2,000; Abcam) was added into the cell suspension, and incubated at $4^{\circ} \mathrm{C}$ for $30 \mathrm{~min}$. Cells were washed with PBS three times. Cells were resuspended in $500 \mu \mathrm{l}$ PBS, and detected by flow cytometry. Data was acquired on an LSRII flow cytometer (BD Biosciences) and analyzed with FlowJo software. Experiments were repeated three times.

Statistical analysis. Statistical data was analyzed by GraphPad Prism version 5.0 software (GraphPad Software, Inc., La Jolla, CA, USA). The results are presented as mean \pm standard error. Differences among $\geq 3$ groups were compared by one-way analysis of variance followed by the Bonferroni post hoc test. Differences between 2 groups were compared by Student's t-test. $\mathrm{P}<0.05$ was considered to indicate a statistically significant difference.

\section{Results}

Derivation and identification of rat retinal progenitor cells and retinal ganglion cells. Retinal progenitor cells and ganglion cells were isolated from rats as described in the methods. Immunofluorescence was utilized to identify these cells. Rat retinal progenitor cells were stained with a primary antibody against Nestin, and retinal ganglion cells were stained with a primary antibody against Thyl. Slides were observed with a fluorescence microscope. It was demonstrated that the isolated retinal progenitor cells were Nestin-positive, and retinal ganglion cells were Thyl-positive, suggesting the success of the isolation (Fig. 2A and B). From the immunofluorescence data, $\sim 40$ to $50 \%$ isolated cells were $\mathrm{Nestin}^{+}$and $\mathrm{Thyl}^{+}$, respectively. Some non-specific positive staining may be observed. cells in a pressure-dependent manner. The retinal progenitor

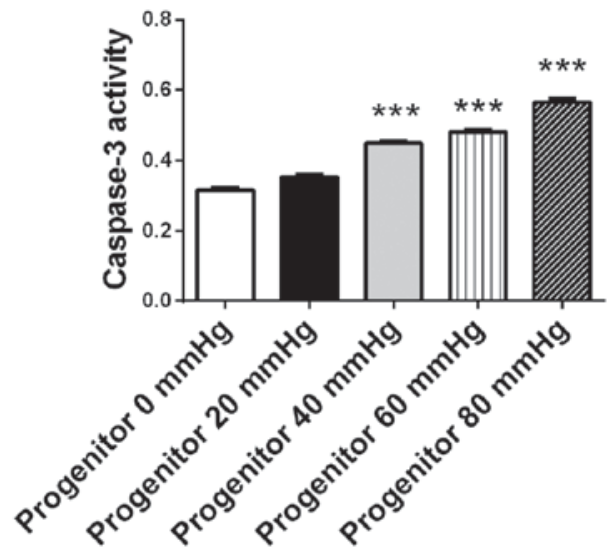

Figure 3. Surrounding pressure induces apoptosis in retinal progenitor cells in a pressure-dependent manner. The retinal progenitor cell mixture was cultured for $48 \mathrm{~h}$ under surrounding pressures of $0,20,40,60$ and $80 \mathrm{mmHg}$. Cellular apoptosis was detected using a caspase-3 assay kit. The activity of caspase- 3 increased in the retinal progenitor cell mixture in a pressure-dependent manner. When the surrounding pressure reached 40,60 and $80 \mathrm{mmHg}$, the activity of caspase- 3 in retinal progenitor cells increased significantly compared with cells that were not under pressure (mean \pm standard error; $n=3$ per group). Experiments were repeated three times. ${ }^{* * *} \mathrm{P}<0.001$ vs. $0 \mathrm{mmHg}$ group.

cell mixture was cultured for $48 \mathrm{~h}$ under surrounding pressures of $0,20,40,60$ and $80 \mathrm{mmHg}$. Cellular apoptosis was detected using a caspase- 3 assay kit. The activity of caspase- 3 increased in the retinal progenitor cell mixture in a pressure-dependent manner. When the surrounding pressure reached 40,60 and $80 \mathrm{mmHg}$, the activity of caspase- 3 in the retinal progenitor cell mixture increased significantly compared with cells that were not under pressure $(0 \mathrm{mmHg}$; $\mathrm{P}<0.001$; Fig. 3$)$. As $40-50 \%$ of the cell mixture constituted retinal progenitor cells, and retinal progenitor cells are more susceptible to increased pressure compared with connective tissue cells or the epithelium, the increase in apoptosis in the cell mixture suggested that this was due to the presence of retinal progenitor cells. These 


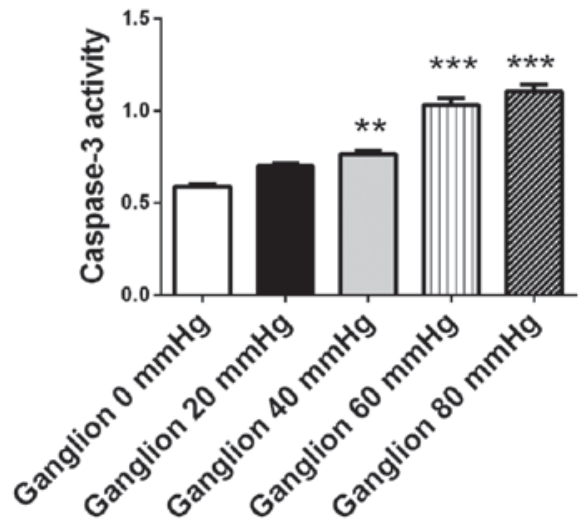

Figure 4. Surrounding pressure induces apoptosis in retinal ganglion cells in a pressure-dependent manner. Retinal ganglion cells were cultured for $48 \mathrm{~h}$ under surrounding pressures of $0,20,40,60$ and $80 \mathrm{mmHg}$. Cellular apoptosis was detected with a caspase- 3 assay kit. The activity of caspase- 3 increased in retinal ganglion cells in a pressure-dependent manner. When the surrounding pressure reached 40,60 and $80 \mathrm{mmHg}$, the activity of caspase-3 in retinal progenitor cells significantly increased compared with cells that were not under pressure (mean \pm standard error; $\mathrm{n}=3$ per group). Experiments were repeated three times. ${ }^{* *} \mathrm{P}<0.01$ and ${ }^{* * *} \mathrm{P}<0.001$ vs. $0 \mathrm{mmHg}$ group.

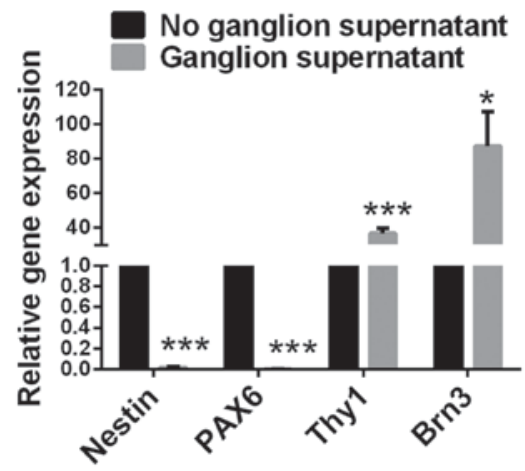

Figure 5. Expression levels of Nestin and PAX6 significantly decrease, and the expression of Thy1 and Brn3 significantly increases in retinal progenitor cells cultured with retinal ganglion cell-conditioned medium. The culture supernatant of rat retinal ganglion cells was collected. Retinal progenitor cells were cultured in retinal ganglion cell-conditioned medium for $72 \mathrm{~h}$ under normal pressure. Retinal progenitor cells that were cultured without retinal ganglion cell-conditioned medium served as a control. The mRNA expression levels of Nestin, PAX6, Thy1 and Brn-3 in retinal progenitor cells was measured by reverse transcription-quantitative polymerase chain reaction. Compared with retinal progenitor cells cultured without ganglion cell-conditioned medium, cells cultured with ganglion cell-conditioned medium exhibited significantly decreased expression levels of Nestin and PAX6, and increased expression levels of Thy1 and Brn3 (mean \pm standard error; $\mathrm{n}=3$ per group). Experiments were repeated three times. ${ }^{*} \mathrm{P}<0.05$ and ${ }^{* * *} \mathrm{P}<0.001$ vs. retinal progenitor cells cultured without retinal ganglion cell-conditioned medium. PAX6, paired box protein 6 ; Brn3, brain-specific homeobox/POU domain protein 3.

results suggested that surrounding pressure induced apoptosis in retinal progenitor cells in a pressure-dependent manner.

Surrounding pressure induces apoptosis in retinal ganglion cells in a pressure-dependent manner. Retinal ganglion cells were cultured for $48 \mathrm{~h}$ under surrounding pressure of $0,20,40,60$ and $80 \mathrm{mmHg}$. Cellular apoptosis was detected using a caspase-3 assay kit. The activity of caspase- 3 increased in retinal ganglion cells in a pressure-dependent manner. When the surrounding pressure reached 40, 60 and $80 \mathrm{mmHg}$, the activity of caspase-3
$0 \mathrm{mmHg}$
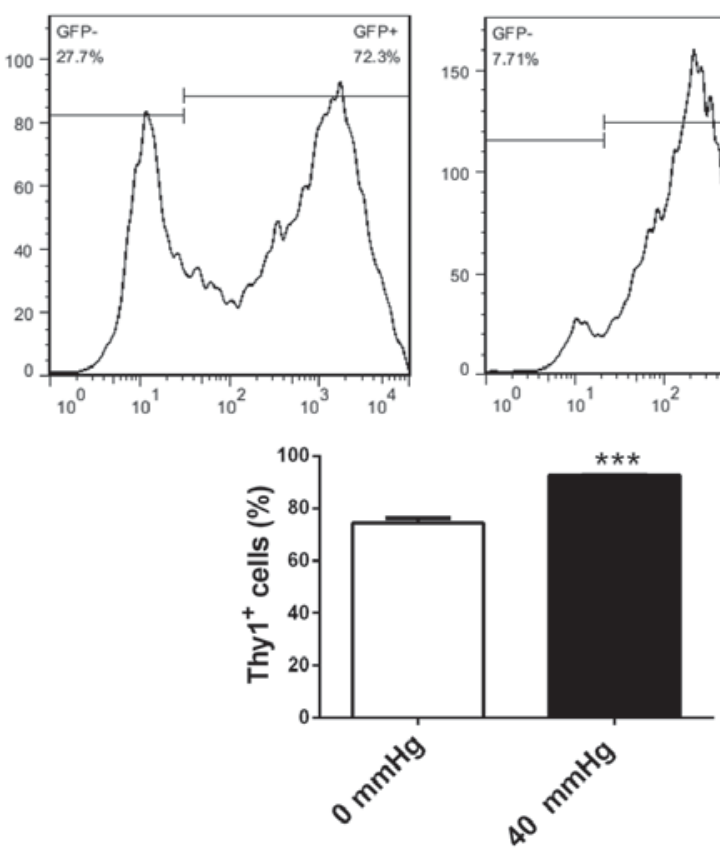

Figure 6. Increased surrounding pressure stimulates differentiation of retinal progenitor cells into retinal ganglion-like cells. Retinal progenitor cells were cultured in retinal ganglion cell-conditioned medium for $72 \mathrm{~h}$ under surrounding pressures of 0 and $40 \mathrm{mmHg}$. Flow cytometry was utilized to evaluate the effects of pressure on the differentiation of retinal progenitor cells into retinal ganglion cells. Retinal ganglion-like cells $\left(\mathrm{Thy} 1^{+}\right)$were stained with GFP. Compared with cells subjected to $0 \mathrm{mmHg}$ pressure, retinal progenitor cells cultured in ganglion cell-conditioned medium under $40 \mathrm{mmHg}$ pressure had increased percentages of Thy1-positive cells (mean \pm standard error; $n=4$ per group). Experiments were repeated four times. ${ }^{* * *} \mathrm{P}<0.001$ vs. retinal progenitor cells that were cultured under $0 \mathrm{mmHg}$. GFP, green fluorescent protein.

in retinal progenitor cells increased compared with cells that were not under pressure $(\mathrm{P}<0.01$ at $40 \mathrm{mmHg} ; \mathrm{P}<0.001$ at 60 and $80 \mathrm{mmHg}$; Fig. 4). The results demonstrated that surrounding pressure may induce apoptosis in retinal ganglion cells in a pressure-dependent manner.

Expression of Nestin and PAX6 significantly decreases, and expression of Thyl and Brn3 increases in retinal progenitor cells cultured with retinal ganglion cell-conditioned medium. The culture supernatant of rat retinal ganglion cells was collected. Retinal progenitor cells were cultured in retinal ganglion cell-conditioned medium for $72 \mathrm{~h}$ under normal pressure. Retinal progenitor cells that were cultured without retinal ganglion cell-conditioned medium served as a control. Gene expression levels of Nestin, PAX6, Thy1 and Brn-3 in retinal progenitor cells were detected by RT-qPCR. Compared with retinal progenitor cells cultured without ganglion cell-conditioned medium, cells cultured with ganglion cell-conditioned medium had significantly decreased expression levels of Nestin and PAX6 ( $\mathrm{P}<0.001)$, and significantly increased expression levels of Thy1 ( $\mathrm{P}<0.001$; Fig. 5) and Brn3 ( $<<0.05$; Fig. 5).

Increased surrounding pressure stimulates differentiation of retinal progenitor cells into retinal ganglion-like cells. Retinal progenitor cells were cultured in retinal ganglion cell-conditioned medium for $72 \mathrm{~h}$ under surrounding 
pressures of 0 and $40 \mathrm{mmHg}$. Flow cytometry was utilized to evaluate the effects of pressure on the differentiation of retinal progenitor cells into retinal ganglion cells. Compared with $0 \mathrm{mmHg}$ pressure, retinal progenitor cells cultured in ganglion cell-conditioned medium under $40 \mathrm{mmHg}$ pressure had increased percentages of Thy1-positive cells $(\mathrm{P}<0.001$; Fig. 6). This suggested that increased surrounding pressure stimulated the differentiation of retinal progenitor cells into retinal ganglion-like cells.

\section{Discussion}

The present study demonstrated that apoptosis in rat retinal progenitor cells and retinal ganglion cells was pressuredependent. Retinal ganglion cell-conditioned medium increased the differentiation of retinal progenitor cells into retinal ganglion-like cells, and the differentiation increased as the surrounding pressure increased.

Various animal models of different species have been used to study glaucoma, including monkeys, dogs, cats, pigs and rodents (14-18). Glaucoma in these animals was either spontaneous or induced. These models have provided valuable information about glaucoma. However, as the molecular mechanism of glaucoma differs among animal species, data obtained from a particular model may not be generalized to all species. Previously, in vitro and ex vivo glaucoma models have been developed to improve the accuracy and repeatability of experimental conditions (19,20). Hydrostatic pressure was applied to cells cultured in vitro and ex vivo. In addition, transgenic mouse glaucoma models that were modified by the introduction of a foreign DNA sequence into a mouse egg, have emerged (21). In the present study, an in vitro glaucoma model was utilized to ensure accuracy and repeatability.

It was revealed that apoptosis in rat ganglion cells was pressure-dependent. In a rat model of glaucoma, elevation of phosphorylated N-methyl-D-aspartate receptor $2 \mathrm{~A}$ by cyclin dependent kinase (cdk)5/p35 was revealed to cause apoptosis in retinal ganglion cells. Apoptosis was ameliorated by inhibiting cdk5/p35 (22). Reactivated Muller cells were demonstrated to release excessive adenosine triphosphate, causing apoptosis in retinal ganglion cells via activation of purinergic receptor P2X 7 receptors (23). The proliferation and apoptosis of retinal ganglion cells was additionally reported to be mediated by the microRNA-187/mothers against decapentaplegic homolog 7 axis. A decrease in miR-187 induced apoptosis and inhibited proliferation in retinal ganglion cells (24). In addition, the apoptosis of retinal ganglion cells has been observed in other retinal diseases. In a rat model of light-induced retinal damage, transcription factor FOS-related antigen 1 was observed to be associated with apoptosis in retinal ganglion cells following light exposure, regulated by p38 mitogen-activated protein kinase (MAPK) through a cell cycle re-entry mechanism (25). Palmitic acid induced apoptosis in retinal ganglion cells through the protein kinase $\mathrm{B} /$ forkhead box protein $\mathrm{O} 1$ signaling pathway (26). The gene expression levels and signaling pathways in retinal ganglion cells that are directly affected by increased surrounding pressure, which may trigger cellular apoptosis, require further investigation.

It was additionally demonstrated in the present study that apoptosis in rat retinal progenitor cells was pressure-dependent.
Various factors may impact on the proliferation of retinal progenitor cells. Activation of the type 5 metabotropic glutamate receptor promoted the proliferation of rat retinal progenitor cells through activation of the phosphatidylinositol 3-kinase and MAPK signaling pathways (27). Mutual antagonism of the paired-type homeobox genes, visual system homeobox 2 and diencephalon/mesencephalon homeobox 1, was demonstrated to regulate retinal progenitor cell cycle exit upstream of cyclin D1 expression (28). Toll-like receptor and MyD88-dependent and -independent pathways were revealed to be negative regulators of proliferation in retinal progenitor cells (29). SUMOylation controlled retinal progenitor proliferation by repressing cell cycle exit in Xenopus laevis (30). Tropomyosin receptor kinase $\mathrm{C}$ signaling was additionally required for retinal progenitor cell proliferation (31). The present study revealed for the first time that increased surrounding pressure induced apoptosis in retinal progenitor cells in a pressure-dependent manner. Increased research efforts are required to elucidate the possible underlying molecular mechanisms.

In addition, the present study revealed that retinal ganglion cell-conditioned medium increased the differentiation of retinal progenitor cells into retinal ganglion-like cells, and differentiation increased as surrounding pressure increased. The differentiation of retinal progenitor cells may be affected by many factors. The yes-associated protein gene was revealed to be essential for the cell cycle progression of retinal progenitor cells, and differentiation towards retinal pigment epithelium in the developing mouse eye (32). Perturbations during the early proliferative stages of retinal progenitor cells fated to be rods and bipolar cells altered the coordinated time-dependent progression of differentiation, and synaptic development (33). Activin/nodal signaling was reported to support the differentiation of retinal progenitor cells in a narrow time window during pluripotent stem cell neutralization (34). The Hippo signaling pathway controlled a switch between retinal progenitor cell proliferation and photoreceptor cell differentiation in zebrafish (35). Vascular endothelial growth factor was reported to activate divergent intracellular signaling components to regulate retinal progenitor cell proliferation and neuronal differentiation (36). In the present study, it was demonstrated that retinal ganglion cell-conditioned medium induced the differentiation of retinal progenitor cells into ganglion-like cells. It is likely that various growth factors were secreted by retinal ganglion cells into the culture medium, which stimulated the differentiation of retinal progenitor cells towards a ganglion direction. Increased surrounding pressure, as a stress factor, may activate the differentiation signaling of retinal progenitor cells towards ganglion regeneration. The specific growth factors or mediators involved, and the differentiation signaling pathway that is switched on in retinal progenitor cells, require further investigation.

In conclusion, the present study demonstrated that apoptosis in rat retinal progenitor cells and retinal ganglion cells was pressure-dependent, and retinal ganglion cell-conditioned medium increased the differentiation of retinal progenitor cells into ganglion-like cells. In addition, differentiation increased as surrounding pressure increased. Although further investigation is required, these results pave the foundation for possible cell therapy for glaucoma. 


\section{Acknowledgements}

The present study was supported by the Joint Specialized Research Fund from Yunnan Provincial Department of Science and Technology and Kunming Medical University (grant no. 2014FB075), and Yunnan Provincial Department of Education Research Fund (grant no. 2014C046Y).

\section{References}

1. Quigley HA and Broman AT: The number of people with glaucoma worldwide in 2010 and 2020. Br J Ophthalmol 90: 262-267, 2006.

2. Sommer A, Tielsch JM, Katz J, Quigley HA, Gottsch JD, Javitt J and Singh K: Relationship between intraocular pressure and primary open angle glaucoma among white and black Americans. The Baltimore Eye Survey. Arch Ophthalmol 109: 1090-1095, 1991

3. Yamazaki M, Omodaka K, Takahashi H and Nakazawa T: Estimated retinal ganglion cell counts for assessing a wide range of glaucoma stages, from preperimetric to advanced. Clin Exp Ophthalmol 45: 310-313, 2017.

4. Hirooka K, Izumibata S, Ukegawa K, Nitta E and Tsujikawa A: Estimating the rate of retinal ganglion cell loss to detect glaucoma progression: An observational cohort study. Medicine (Baltimore) 95: e4209, 2016.

5. Salehi H, Amirpour N, Razavi S, Esfandiari E and Zavar R: Overview of retinal differentiation potential of mesenchymal stem cells: A promising approach for retinal cell therapy. Ann Anat 210: 52-63, 2017.

6. Jagatha B, Divya MS, Sanalkumar R, Indulekha CL, Vidyanand S, Divya TS, Das AV and James J: In vitro differentiation of retinal ganglion-like cells from embryonic stem cell derived neural progenitors. Biochem Biophys Res Commun 380: 230-235, 2009

7. Huang C, Zhang J, Ao M, Li Y, Zhang C, Xu Y, Li X and Wang W: Combination of retinal pigment epithelium cell-conditioned medium and photoreceptor outer segments stimulate mesenchymal stem cell differentiation toward a functional retinal pigment epithelium cell phenotype. J Cell Biochem 113: 590-598, 2012.

8. Qiu G, Seiler MJ, Thomas BB, Wu K, Radosevich M and Sadda SR: Revisiting nestin expression in retinal progenitor cells in vitro and after transplantation in vivo. Exp Eye Res 84: 1047-1059, 2007.

9. Davis LK, Meyer KJ, Rudd DS, Librant AL, Epping EA, Sheffield VC and Wassink TH: Pax6 3' deletion results in aniridia, autism and mental retardation. Hum Genet 123: 371-378, 2008.

10. Suzuki N, Shimizu J, Takai K, Arimitsu N, Ueda Y, Takada E, Hirotsu C, Suzuki T, Fujiwara N and Tadokoro M: Establishment of retinal progenitor cell clones by transfection with Pax6 gene of mouse induced pluripotent stem (iPS) cells. Neurosci Lett 509: 116-120, 2012.

11. Huang W, Fileta J, Guo Y and Grosskreutz CL: Downregulation of Thy1 in retinal ganglion cells in experimental glaucoma. Curr Eye Res 31: 265-271, 2006.

12. Jain V, Ravindran E and Dhingra NK: Differential expression of Brn3 transcription factors in intrinsically photosensitive retinal ganglion cells in mouse. J Comp Neurol 520: 742-755, 2012.

13. Livak KJ and Schmittgen TD: Analysis of relative gene expression data using real-time quantitative PCR and the 2(-Delta Delta C(T)) method. Methods 25: 402-408, 2001.

14. Vecino E: Animal models in the study of the glaucoma: Past, present and future. Arch Soc Esp Oftalmol 83: 517-519, 2008 (In Spanish).

15. Rasmussen CA and Kaufman PL: Primate glaucoma models. J Glaucoma 14: 311-314, 2005.

16. Brooks DE: Glaucoma in the dog and cat. Vet Clin North Am Small Anim Pract 20: 775-797, 1990.

17. Ruiz-Ederra J, García M, Hernández M, Urcola H, HernándezBarbáchano E, Araiz J and Vecino E: The pig eye as a novel model of glaucoma. Exp Eye Res 81: 561-569, 2005.

18. Pang IH and Clark AF: Rodent models for glaucoma retinopathy and optic neuropathy. J Glaucoma 16: 483-505, 2007.
19. Wax MB, Tezel G, Kobayashi S and Hernandez MR: Responses of different cell lines from ocular tissues to elevated hydrostatic pressure. Br J Ophthalmol 84: 423-428, 2000.

20. Ishikawa M, Yoshitomi T, Zorumski CF and Izumi Y: Effects of acutely elevated hydrostatic pressure in a rat ex vivo retinal preparation. Invest Ophthalmol Vis Sci 51: 6414-6423, 2010.

21. Harada T, Harada C, Nakamura K, Quah HM, Okumura A, Namekata K, Saeki T, Aihara M, Yoshida H, Mitani A and Tanaka K: The potential role of glutamate transporters in the pathogenesis of normal tension glaucoma. J Clin Invest 117: 1763-1770, 2007.

22. Chen J, Miao Y, Wang XH and Wang Z: Elevation of p-NR2A(S1232) by $\mathrm{Cdk} 5 / \mathrm{p} 35$ contributes to retinal ganglion cell apoptosis in a rat experimental glaucoma model. Neurobiol Dis 43: 455-464, 2011.

23. Xue B, Xie Y, Xue Y, Hu N, Zhang G, Guan H and Ji M: Involvement of P2X7 receptors in retinal ganglion cell apoptosis induced by activated Müller cells. Exp Eye Res 153: 42-50, 2016.

24. Zhang QL, Wang W, Li J, Tian SY and Zhang TZ: Decreased miR-187 induces retinal ganglion cell apoptosis through upregulating SMAD7 in glaucoma. Biomed Pharmacother 75: 19-25, 2015.

25. Liu X, Yang X, Zhu R, Dai M, Zhu M, Shen Y, Fang H, Sang A and Chen H: Involvement of Fra-1 in retinal ganglion cell apoptosis in rat light-induced retina damage model. Cell Mol Neurobiol 37: 83-92, 2017.

26. Yan P, Tang S, Zhang H, Guo Y, Zeng Z and Wen Q: Palmitic acid triggers cell apoptosis in RGC-5 retinal ganglion cells through the Akt/FoxO1 signaling pathway. Metab Brain Dis 32: 453-460, 2017.

27. Zhang Z, Hu F, Liu Y, Ma B, Chen X, Zhu K, Shi Y, Wei T, Xing Y, Gao Y, et al: Activation of type 5 metabotropic glutamate receptor promotes the proliferation of rat retinal progenitor cell via activation of the PI-3-K and MAPK signaling pathways. Neuroscience 322: 138-151, 2016.

28. Wong L, Power N, Miles A and Tropepe V: Mutual antagonism of the paired-type homeobox genes, vsx 2 and dmbx1, regulates retinal progenitor cell cycle exit upstream of ccnd1 expression. Dev Biol 402: 216-228, 2015.

29. Shechter R, Ronen A, Rolls A, London A, Bakalash S, Young MJ and Schwartz M: Toll-like receptor 4 restricts retinal progenitor cell proliferation. J Cell Biol 183: 393-400, 2008.

30. Terada K and Furukawa T: Sumoylation controls retinal progenitor proliferation by repressing cell cycle exit in Xenopus laevis. Dev Biol 347: 180-194, 2010.

31. Das I, Sparrow JR, Lin MI, Shih E, Mikawa T and Hempstead BL: Trk C signaling is required for retinal progenitor cell proliferation. J Neurosci 20: 2887-2895, 2000.

32. Kim JY, Park R, Lee JH, Shin J, Nickas J, Kim S and Cho SH: Yap is essential for retinal progenitor cell cycle progression and RPE cell fate acquisition in the developing mouse eye. Dev Biol 419: 336-347, 2016

33. Chaney SY, Mukherjee S, Giddabasappa A, Rueda EM, Hamilton WR, Johnson JE Jr and Fox DA: Increased proliferation of late-born retinal progenitor cells by gestational lead exposure delays rod and bipolar cell differentiation. Mol Vis 22: 1468-1489, 2016.

34. Bertacchi M, Lupo G, Pandolfini L, Casarosa S, D'Onofrio M, Pedersen RA, Harris WA and Cremisi F: Activin/nodal signaling supports retinal progenitor specification in a narrow time window during pluripotent stem cell neuralization. Stem Cell Reports 5: 532-545, 2015.

35. Asaoka Y, Hata S, Namae M, Furutani-Seiki M and Nishina H: The Hippo pathway controls a switch between retinal progenitor cell proliferation and photoreceptor cell differentiation in zebrafish. PLoS One 9: e97365, 2014.

36. Hashimoto T, Zhang XM, Chen BY and Yang XJ: VEGF activates divergent intracellular signaling components to regulate retinal progenitor cell proliferation and neuronal differentiation. Development 133: 2201-2210, 2006.

This work is licensed under a Creative Commons Attribution-NonCommercial-NoDerivatives 4.0 International (CC BY-NC-ND 4.0) License. 